\title{
Behavioural and Psychological Factors That Influence the Usage of Formal Financial Services Among the Low Income Households
}

\author{
Binoy Thomas ${ }^{1} \&$ P. Subhashree ${ }^{1}$ \\ ${ }^{1}$ VIT Buinsess School, Vellore Institute of Technology, Vellore, India \\ Correspondence: P. Subhashree, Professor, VIT Buinsess School, Vellore Institute of Technology, Vellore, India. \\ E-mail: subhashree.p@ vit.ac.in
}

Received: April 9, 2020

Accepted: June 28, 2020

Online Published: September 5, 2020

doi:10.5430/rwe.v11n5p326

URL: https://doi.org/10.5430/rwe.v11n5p326

\begin{abstract}
The emerging economies need to frame and implement effective financial inclusion policies for sustainable development and growth. Recent initiative of India that every Low Income Households (LIHs) has a bank account is a sweeping success; but the flipside is that half of these accounts are either inactive or less active, which raises concern. In this context, this research attempts to identify the behavioural and psychological factors that influence the usage of formal financial services (FFS) among LIHs in India. Theory of Planned Behaviour is used as the base theoretical model, in which 'Habit' was introduced as a moderating variable that interacts with Behavioural Intention to influence Actual Usage. Data was collected from 253 respondents and analysed using SmartPLS 3.0. This study revealed that the exogenous variables Attitude, Subjective Norms, Perceived Behavioural Control positively influenced the intention to use FFS; moreover, Habit negatively moderated the BI-AU relationship. Therefore, the policy makers on financial inclusion drive may consider these identified factors in their mission to improve the usage of FFS among LIHs, and to curtail the informal or alternative financial services.
\end{abstract}

Keywords: financial inclusion, formal financial services, theory of planned behaviour, behavioural factors, psychological factors, continued usage, low income households

\section{Introduction}

In the recent years, World Bank, G20 nations and IMF have endorsed that financial inclusion is one of the key factors for sustainable global development, especially in developing economies (Camera \& Tuesta 2014; Cihak et al 2016). Kodan \& Chhikara (2013) observed that $1 \%$ increase in the financial inclusion leads to $0.142 \%$, on an average, increase in the Human Development Index (HDI). Recent political and financial policies of India, focuses on financial inclusion for creating a corruption-free, pro-common man government. As a milestone among the various initiatives in India, 362.5 million new bank accounts (as on 17 July 2019) have been opened under Pradhan Mantri Jan-Dhan Yojana (financial inclusion scheme) during last five years.

According to Global Findex Database (2017), India has witnessed a tremendous increase in the number of bank accounts opened over the past 3 years (53\% in 2014 to $80 \%$ of the population in 2017). But this 'greater access' into bank accounts has not been translated into proportionate increase in its 'continued usage' and regular feature in the lives of most Indians. Nearly half of the accounts (48\%) remain inactive, i.e. no deposit and no withdrawal have taken place during the past one year. Inactive bank accounts and infrequent use of active bank accounts is a concern for banks and government, as it questions the policy decision and costs invested towards financial inclusion. Many other researchers also have pointed out that continued usage and balance-building of the bank accounts are the areas where future improvements in the financial inclusion initiatives are required (Fiorillo et al 2014; Sinha \& Azad 2018; Ranjani \& Bapat 2015; Mani 2016).

Financial inclusion is defined as the process of ensuring access to formal financial services (FFS) for all sections of the society, especially to the low income groups, at affordable cost (CRISIL Inclusix 2018; Kim 2016; Rangarajan Committee 2008; Reserve Bank of India 2011). The mission of financial inclusion never ends up with providing 'mere access'; rather it is extended towards the 'continuous usage' of FFS (Allen et al 2012, 2016; Nandru et al 2016; Sahay et al 2015).

In the research literature on financial inclusion, the major focus has been on supply-centric factors (penetration and accessibility); the demand-centric factor (usage) has not been adequately emphasized (Arora 2012; Joshi 2014). RBI (2014) have pointed out that there is a genuine necessity for conducting indepth studies on the demand side factors 
that lead into the continued usage of FFS. The research focus of financial inclusion has recently been shifted more towards the actual use of existing bank accounts (Beck 2016). Hence, the present study will discuss on the 'usage' dimension.

Most of the research studies on the usage of bank accounts or other financial services have been concentrated only on the demographic, economic, and structural factors; the studies that discuss the role of behavioural and psychological elements are very few. Moreover, the multivariate studies in this area are fewer. In this context, the present study would concentrate more on the behavioural and psychological factors.

Most of the existing theories on the usage behaviour of bank accounts are based on the middle or high income households; the studies that discuss the usage behaviour of the low income households (LIHs) are found to be very few. If the predictors of the usage behaviour applied to middle or high income people are directly applied to low income individual, it might give a twisted perception in the context where they are influenced by diverse influential factors. Agbaeze \& Onwuka (2014), Idzik (2016), Mukhopadhyay (2016), and Tulasi et al. (2017) have rightly pointed out the necessity of precisely mapping the economic behaviour and financial needs of LIHs. Thus, this study is designed to focus on this less researched segment of LIHs.

Further, review of literature, indicated that habit influence the actual behaviour, however, the exact role of habit remains unclear (Kim 2012; Limayem et al. 2003, 2007). Triandis (1980) stated that habit can exercise either a direct effect or an interactive effect on actual behaviour. In this context, the present study re-examines what is the nature of the impact of habit on Behavioural intention and on Actual usage behaviour.

The review of the existing literature on the financial inclusion and the usage of formal financial services (FFS) reveals that majority of the studies has concentrated on the influence of economic factors neglecting the non-economic factors. So, the present study attempts to fill this gap that exists in the literature by discussing the ignored area, i.e. the role of behavioural and psychological factors (non-economic factors). Moreover, the existing literature on the usage of FFS has been mostly based on the data collected from the high income individuals; very low emphasis has been laid for mapping the unique factors of the low income households (LIHs) and individuals. So, the present study has collected data from LIHs and attempted to sketch the factors that influence the usage of FFS among them. Thus, the present study discusses at least towards the two discarded area of the previous literature, i.e. non-economic (behavioural and psychological) factors, the segment of LIHs. This study would contribute towards moulding the policies and strategies for improving the usage of FFS and the financial inclusion level.

In the context of the above discussed research gaps, the following research questions are framed: (i) What are the various behavioural and psychological factors that influence the usage of the bank accounts among LIHs? (ii) Do habit moderates the relationship between behavioural intention and actual usage behaviour? Based on these research questions, the research objectives of the present study are formulated: (i) To identify the behavioural and psychological factors that influence the usage of FFS among LIHs; (ii) To find whether habit moderates the relationship between behavioural intention and actual usage behaviour.

\section{Review of Literature}

Researchers have stressed on the role of behavioural and psychological dispositions of individuals households to explain the usage financial services (Blanco et al 2015; Riitsalu 2018; Mahapatra et al 2019; Ali et al 2014; Gabor \& Brooks 2016; Fiorillo et al 2014; McNair et al 2016). Some of the identified factors are over-confidence (Asikoglu \& Boyukaslan 2016), perceived self-efficacy (Brounen et al 2016), financial goals (Curley et al 2009; Vyas 2012), social Norms (Cai et al 2013; Doi et al 2012), trustworthiness (Bhanot et al 2012), impulsivity or self-control (Gathergood 2012; Gathergood \& Weber 2014), fear of rejection (Ranjani \& Bapat 2015), social status (Kempson 2016; Kempson et al 2017), etc. Among the studies on LIHs, Miotto \& Parente (2015) have found that the personal characteristics such as self-control, propensity to plan for the future, etc. affected the financial management styles.

Behavioural economic theories such as Behavioural Life Cycle Hypothesis (Sheffrin \& Thaler 1988), Permanent Income Hypothesis (Thaler \& Sheffrin 1981), Regret Theory (Loomes \& Sugden 1982), Prospect theory (Kahneman \& Tversky 1979), etc. substantiate that the behavioural and psychological factors influence the financial behaviour of households. So these theories can be considered as the theoretical foundation of the present study.

\subsection{Theory of Planned Behaviour}

Among the various established socio-psychological models, Theory of Planned Behaviour (TPB) has been widely accepted as one of the most significant conceptual frameworks for predicting the human social behaviour (Zinser 2015; Nosek et al 2010). According to Ajzen (1991), TPB model states that the Intention to perform a particular Behaviour (BI) is the immediate antecedent of the Actual Behaviour (AB) and that the BI is mainly predicted by three factors, i.e. Attitudes (AT) towards behaviour, Subjective Norms (SN), Perceived Behavioural Control (PBC) 
(Ajzen 1991). Many researchers have recently attempted to identify the predictors of financial behaviour using the TPB model (Bamforth et al 2017; Kaur \& Kaushik 2016; Magendansa et al 2017; Mosalamy \& Metawie 2018; Phan \& Zhou 2014; Raut et al 2018, Zinser 2015).

\subsection{Hypothesis Development}

2.2.1 Attitude [AT]: In the context of financial decision making, many researchers (Borden et al 2008; Funfgeld \& Wang 2009; Kaiser et al 2007; Michael 2011) have found that the financial behaviour can be predicted in a better way when the Attitude of an individual is known. So, we can reasonably assume:

H1: AT positively predicts the BI to use FFS.

2.2.2 Subjective Norms [SN]: Researchers have been found that $\mathrm{SN}$ is a direct and immediate determinant of BI (Ajzen 1991; Fishbein \& Ajzen 1975; Taylor \& Todd 1995; Venkatesh \& Davis 2000). This effect of SN on BI is called the Compliance Effect. In the domain of financial services, $\mathrm{SN}$ is found to exert positive influence on the economic behaviour of households (Asikoglu \& Boyukaslan 2016; Mauldin et al 2016; Mehla \& Ghawat 2014; Koropp et al 2014; Roy \& Sapre 2016). So, we propose:

$\mathrm{H} 2$ : SN positively predicts the BI to use FFS.

2.2.3 Perceived Behavioural Control [PBC]: Researches, in the context of financial decision making, state that PBC positively explains considerable variance in BI (Mahastanti \& Hariady 2014; Phan \& Zhou 2014). PBC influences and predicts the financial behaviour of individual in two ways - (i) PBC directly impacts the Behaviour; (ii) PBC indirectly impacts Behaviour through BI. So, we propose:

$\mathrm{H} 3$ : $\mathrm{PBC}$ positively predicts the $\mathrm{BI}$ to use FFS.

H4: PBC positively predicts the Behaviour (Actual Usage).

2.2.4 Behavioural Intention [BI]: Various socio-psychological models have proved that BI is the immediate cognitive antecedent of behaviour (Fishbein \& Ajzen 1975; Ajzen 1991; Davis 1989; Bhattacherjee 2001). So, we propose:

H5: BI positively predicts the Behaviour.

2.2.5 Habit as Moderator: The present study has incorporated the construct 'Habit' (HA) as moderator into TPB model. Ajzen (1991) has suggested incorporating additional variables into the TPB model if the newly added variables capture a significant proportion of the variance in intention or behaviour after the current variables of the theory have been taken into account. The Expectation - Confirmation Theory of Bhattacherjee (2001), Triandis (1980) and Verplanken et al (1997) have supported moderator role of HA by stating that the relationship of BI on Behaviour is moderated by HA. HA exerts a 'suppressing effect' on the relationship between BI and Behaviour (Limayem \& Cheung 2008; Limayem et al 2007; Kim 2012). It means HA (the suppressor variable) negatively moderates the link between BI and Behaviour. In the context of TPB model, Moons \& Pelsmacker (2015) has used HA as the moderator and it increased the prediction of the behaviour. So, we propose:

H6: HA moderates the relationship between BI and Behaviour.

\section{Proposed Model}

Based on the review of literature, a structural model is proposed for further statistical validation and empirical testing. According to the proposed model (Figure 1), AT, SN, PBC predicts BI; BI and PBC predict AU. HA moderates BI AU relationship.

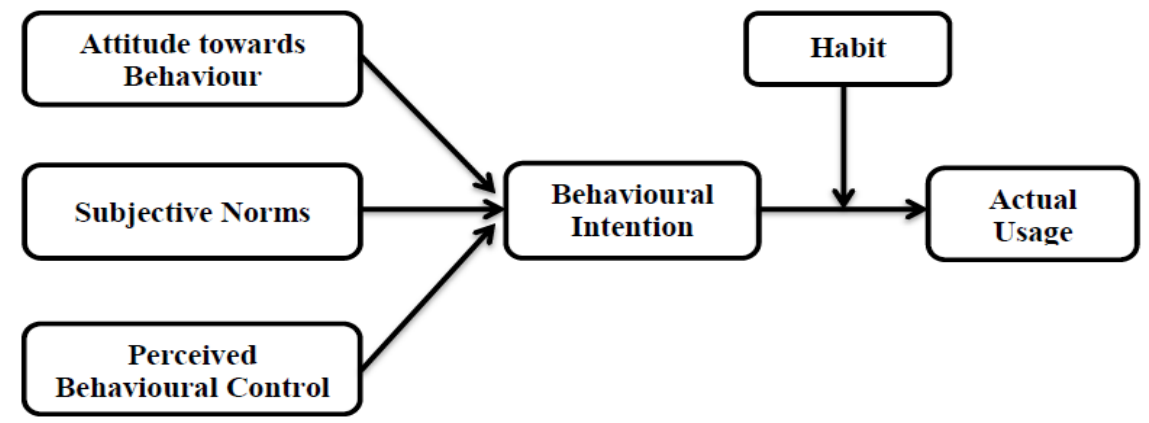

Figure 1. Proposed Structural Model 


\section{Research Methodology}

This research is descriptive that deploys purposive sampling method, survey method to collect data through structured questionnaire. The respondents of the questionnaire are LIHs, i.e. the families who earn less than Rs.3 Lakhs per annum. Pilot study was conducted on 30 samples. Minor modifications in the wordings of the questionnaire were made according to the suggestions proposed by the respondents. Then, the final questionnaire was distributed among 300 LIH respondents; 279 questionnaires (93\%) were received back. Six questionnaires were removed since they included unfilled responses for more than $20 \%$ of the total questions); another three questionnaires were removed because they were filled carelessly either by providing same answer for all questions, or by answering in a specific pattern. 270 questionnaires were considered for the final data analysis. The criterion for minimum sample size is met, i.e. at least 5 respondents per measurement items (Hair et al 2009; Kline 2011).

Theory of Planned Behaviour (Ajzen 1991) has been adopted as the base model for carrying out the study. Based on the previous literature, the moderator HA has been incorporated into the base model. Totally, 6 constructs and 19 measurement items have been used in this present research study. Each measurement item was measured using 5 Point Likert Scale, ranging from 'Strongly Disagree' (=1) to 'Strongly Agree' (=5). The questionnaire was originally prepared in English language and was later translated into the vernacular language of the respondents. Forward-back translation procedure (Brislin 1986) was followed for ensuring the accuracy of translation process. The content validity was ensured in consultation with the experts. The construct validity and further statistical analysis was conducted using SPSS 22.0, and SmartPLS 3.0.

In the present study, $\mathrm{AT}, \mathrm{SN}$, and PBC are the independent variables; $\mathrm{BI}$ is the mediator; Behaviour (Actual Usage) is the dependent variable; HA is a moderator in the relationship between BI and Behaviour. As shown in Table 1, the measurement scales used for the study are: Attitude, Subjective Norm, Perceived Behavioural Control, Behavioural Intention (Ajzen 1991) and Habit (Limayem et al. 2007). Actual Usage is measured through usage frequency, amount of transactions, types of financial services availed, and types of banking services availed.

Table 1. Scales used for the study

\begin{tabular}{llll}
\hline Constructs & & No of Items & Scales Adopted from \\
\hline Attitude & {$[\mathrm{AT}]$} & 4 & Ajzen (1991) \\
Subjective Norm & {$[\mathrm{SN}]$} & 2 & Ajzen (1991) \\
Perceived Behavioural Control & {$[\mathrm{PBC}]$} & 3 & Ajzen (1991) \\
Behavioural Intention & {$[\mathrm{BI}]$} & 3 & Ajzen (1991) \\
Habit & {$[\mathrm{HA}]$} & 3 & Limayem et al. (2007) \\
\hline
\end{tabular}

\section{Measurement Model}

The construct validity of the measurement model was assessed using the Convergent validity and the discriminant validity. Convergent validity was measured by Outer loading, and Average variance extracted (AVE); discriminant validity through Cross-loadings, Fornell-Larker criterion test, and Heterotrait - Monotrait (HTMT) Ratio of Correlations.

\subsection{Convergent Validity}

The outer loadings of all the items to their corresponding constructs were above the threshold value of 0.700 (Hair et al 2014). The outer loadings of the items were: AT (.856, .836, .882, .803); SN (.892, .907); PBC (.905, .922, .888); $\mathrm{BI}(.871, .830, .820)$; $\mathrm{HA}(.838, .899, .830)$; AU $(.829, .849, .854, .857)$. As seen in Table 2 , AVE of all the constructs were sufficiently above the threshold value, i.e. $.714(\mathrm{AT}), .809(\mathrm{SN}), .820(\mathrm{PBC}), .707(\mathrm{BI}), .734(\mathrm{HA})$, and .718 (AU). Since the t-values and significance values met the threshold value, all the items were retained for further analysis. 
Table 2. Construct reliability and validity

\begin{tabular}{llllll}
\hline & $\begin{array}{l}\text { No of } \\
\text { Items }\end{array}$ & $\begin{array}{l}\text { Cronbach's } \\
\text { Alpha }\end{array}$ & rho_A & $\begin{array}{l}\text { Composite } \\
\text { Reliability }\end{array}$ & $\begin{array}{l}\text { Average Variance } \\
\text { Extracted }\end{array}$ \\
\hline AT & 4 & 0.866 & 0.869 & 0.909 & 0.714 \\
SN & 2 & 0.765 & 0.767 & 0.895 & 0.809 \\
PBC & 3 & 0.890 & 0.891 & 0.932 & 0.820 \\
BI & 3 & 0.793 & 0.795 & 0.879 & 0.707 \\
HA & 3 & 0.820 & 0.849 & 0.892 & 0.734 \\
AU & 4 & 0.869 & 0.870 & 0.911 & 0.718 \\
\hline
\end{tabular}

\subsection{Discriminant Validity}

No issues of cross loadings (Chin, 1998) were reported. All the items loaded more into the theoretically related constructs rather than into theoretically unrelated constructs. There was at least a difference of 0.232 between the item-construct loadings and cross-loadings. Multi-collinearity were checked; all the Variance inflation factors values were below at least 3.566, which is under the threshold value of maximum 5 (Ringle et al., 2015). Fornell-Larcker (1981) criterion for assessing the discriminant validity was checked; the AVE square root of each construct was higher than its correlation with other constructs. As shown in Table 3, HTMT ratio of correlations between the constructs was below the threshold value of maximum of .900 (Henseler et al. 2015).

Table 3. Heterotrait-Monotrait (HTMT) ration of Correlations

\begin{tabular}{llllll}
\hline Constructs & AT & AU & BI & HA & PBC \\
\hline AU & 0.567 & & & & \\
BI & 0.711 & 0.798 & & & \\
HA & 0.107 & 0.262 & 0.090 & & \\
PBC & 0.592 & 0.447 & 0.677 & 0.070 & \\
SN & 0.395 & 0.419 & 0.714 & 0.079 & 0.410 \\
\hline
\end{tabular}

\subsection{Reliability (Internal Consistency)}

As shown in Table 2, Cronbach's alpha coefficient of the constructs were .866 (AT), .765 (SN), 890 (PBC), .793 (BI), .820 (HA), and .869 (AU). Joreskog's Rho_A values were .869 (AT), .767 (SN), .891 (PBC), 795 (BI), .849 (HA), and .870 (AU). Composite reliability values were 0.909 (AT), 0.895 (SN), 0.932 (PBC), 0.879 (BI), 0.892 (HA), and 0.911 (AU). All the values were above the threshold level, i.e. .700 (Hair et al., 2006). The significance levels (p-value) for all the constructs were below 0.01 .

\section{Result Analysis and Discussions}

\subsection{Path Coefficient \& T-Values}

As seen in Table 4, path coefficient, t-statistics and significance (p) values among the constructs are: AT=>BI (.337, $7.106,<.01) ; \mathrm{SN}=>\mathrm{BI}(.359,8.574,<.01) ; \mathrm{PBC}=>\mathrm{BI}(.273,5.336,<.01) ; \mathrm{PBC}=>\mathrm{AU}(.058,1.120, .263) ; \mathrm{BI}=>\mathrm{AU}$ $(.663,17.208,<.01)$. In the statistical analysis, the path coefficient and t-statistics of all the relationship, except $\mathrm{PBC}=>\mathrm{AU}$, are above the threshold value, i.e. .1 and 1.946 respectively. $\mathrm{PBC}=>\mathrm{AU}$ path is found to be insignificant. It means that AT, SN and PBC directly and positively influenced BI; BI positively influence and predicts AU. PBC does not influence AU directly, but influence indirectly through BI. 
Table 4. Path Coefficients, T Statistics, P Values

\begin{tabular}{llll}
\hline Path & Path Coefficients & T Statistics & P Values \\
\hline AT -> BI & 0.337 & 7.106 & $<0.01$ \\
SN -> BI & 0.359 & 8.574 & $<0.01$ \\
PBC -> BI & 0.273 & 5.336 & $<0.01$ \\
PBC -> AU & 0.058 & 1.120 & 0.263 \\
BI -> AU & 0.663 & 17.208 & $<0.01$ \\
(BI*HA) -> AU & 0.207 & 4.412 & $<0.01$ \\
Moderating Effect & & & \\
\hline
\end{tabular}

This established relationship between AT and BI goes along the findings of other researchers (Panda 2019; Amin et al 2014; Borden et al 2008; Funfgeld \& Wang 2009) in the context of FFS. The favourable AT towards FFS and financial institutions will lead to an increase in BI of the customers to use FFS. SN is found to be the most influential factor among the three predictors of BI. The SN-BI relationship is consistent with previous studies (Ali \& Raza 2015; Amin et al 2014; Cai et al 2013; Koropp et al 2014; Mehla \& Ghawat 2014; Roy \& Sapre 2016). PBC also influence and predict BI. This finding is supported by previous studies in the context of financial decision making (Amin et al 2014; Mahastanti \& Hariady 2014; Phan \& Zhou 2014). The facilities, resources, and skills of the customers have an active and influential role in deciding the BI.

\section{$6.2 R$-Square}

The statistical analysis reveals that, as shown in Table 5, the R-Square value of $\mathrm{BI}$ is $0.555(\mathrm{t}=15.129 ; \mathrm{p}=<0.01)$ and of $\mathrm{AU}$ is $0.521(\mathrm{t}=11.743 ; \mathrm{p}=<0.01)$. It means $55.5 \%$ of the variances in the $\mathrm{BI}$ to use FFS is predicted by the exogenous variables AT, SN, and PBC. BI as exogenous variable, together with HA (moderator), predicts $52.1 \%$ of the variances AU to use FFS.

Table 5. R Square, R Square Adjusted, T Statistics, P Values

\begin{tabular}{lllll}
\hline & R Square & R Square Adjusted & T Statistics & P Values \\
\hline BI & 0.555 & 0.555 & 15.129 & $<0.01$ \\
AU & 0.521 & 0.523 & 11.743 & $<0.01$ \\
\hline
\end{tabular}

\subsection{Moderation Effect of Habit}

In addition to the direct effect, $\mathrm{HA}$ is proved to have a moderating effect (interactive effect along with $\mathrm{BI}$ ) on the relationship between $\mathrm{BI}$ and $\mathrm{AU}$. By the inclusion of the moderation effect of HA, the predictably (R-square value) of the model has been raised from 0.481 to 0.521 . The path coefficient, T-statistics and significance (p-values) of the moderating effect $((\mathrm{BI} * \mathrm{HA})=>\mathrm{AU})$ are $.207,4.412$, and $<.01$ respectively. The moderating role of HA is compatible with the previous studies (Aarts et al 2008; Bhattacherjee 2001; Limayem \& Cheung 2008; Limayem et al 2007; Kim 2012; Triandis 1980; Verplanken et al 2011).

\section{Conclusions}

Measuring behavioural and psychological factors that influence the usage of FFS among LIHs is relatively a new domain of research; therefore, very few studies have been done so far in the area. This study makes significant contribution into specific part of the literature, i.e. behavioural and psychological antecedents of usage of FFS.

Managerial Implications: The practioners in the area of financial inclusion have to frame and implement strategies to improve the positive attitude of LIHs towards the use of FFS. More awareness programs related to usefulness and trustworthiness of FFS are to be conducted; LIHs have to be made aware how the available FFS are compatible with their transaction patterns. Since LIHs are highly influenced by their peer group and co-workers, the group training programs would be more suitable among them when introducing various initiatives to promote the usage of FFS. Moreover, Actual Usage of FFS can be improved by introducing dedicated efforts to inculcate the habit of interaction with FFS. When LIHs are habituated towards FFS, the influence of BI is reduced. So, governments and the financial institutions can nudge LIHs to make use of FFS through various concrete schemes; LIHs will consequently start to use as the new pattern of financial transactions. 
Policy Implications: This research is an attempt to improve the effective implementation of financial inclusion schemes in India by gaining deep insights on the perceived ease-of use, usefulness, trust and product compatibility that leads to continued usage of the bank accounts. The policy makers may consider the identified factors - attitude, subjective norms, perceived behavioural control, and habit - while framing further financial inclusion policies. It would help the policy makers for promoting the usage of FFS, and curtailing the usage of informal or alternative financial services. Subsequently, it will contribute towards efforts for poverty alleviation and sustainable development.

Limitations: In spite of its significant contributions, the present study has some limitations. Very limited previous literature is available in this domain. The tool of data collection (questionnaire) was found to be incompatible at least for some LIH respondents, because they were not comfortable with formal language used in the structured questionnaire. The samples for the study were conducted only from Kerala region; it may limit the external validity of the results and generalizability of the findings.

Scope for future research: Future researches may consider additional exogenous variables such as trust, self-control, compatibility, behaviour of bank personnel, etc. and estimate its effects on BI to use FFS. The variables can also be viewed from the perspective of the finance personnel; it may contribute a better understanding of the phenomenon. The proposed model can be tested in different geographical and cultural contexts; it may make these studies more robust. Moreover, further research may design a combination of qualitative and quantitative methods; personal interview method may be a more suitable tool for retrieving information from LIHs.

\section{References}

Ali, P., Ramsay, I., \& Read, C. (2014). Behavioural law and economics: regulatory reform of consumer credit and consumer financial services. Common Law World Review, 43(4). https://doi.org/10.2139/ssrn.2524131

Allen, F., Demirguc-Kunt, A., Klapper, L., \& Martinez, S. (2012). The foundations of financial inclusion understanding ownership and use of formal accounts. Policy Research Working Paper 6290, World Bank, Washington, DC. Retrieved from http://documents.worldbank.org/curated/en/348241468329061640/The-foundations-of-financial-inclusion-unde rstanding-ownership-and-use-of-formal-accounts

Amin, H., Rahman, A., \& Razak, D. (2014). Consumer acceptance of Islamic home financing. International Journal of Housing Markets and Analysis, 7(3), 307-332. Retrieved from https://econpapers.repec.org/article/emeijhmap/v_3a7_3ay_3a2014_3ai_3a3_3ap_3a307-332.htm

Blanco, L., Ponce, M., Gongora, A., \& Duru, O. (2015). A qualitative analysis of the use of financial services and saving behaviour among older African Americans and Latinos in the Los Angeles Area. SAGE Open, 5(1). https://doi.org/10.1177/2158244014562388

Brislin, R. (1986). The wording and translation of research instruments. In W. Lonner, \& J. Berry (Eds.), Cross-cultural Research and Methodology Series, Vol. 8, Field Methods in Cross-cultural Research (pp. 137-164). Sage Publications Inc., CA. Retrieved from http://www.oalib.com/references/15110451

Byrne, B. (1994). Structural equation modelling with EQS and EQS/Windows. Thousand Oaks, CA: Sage Publications. Retrieved from https://dl.acm.org/doi/book/10.5555/528620

Chin, W. (1998). The partial least squares approach for structural equation modeling. In G. Marcoulides (Ed.), Modern Methods for Business Research (pp. 236-295). Lawrence Erlbaum Associates, London. Retrieved from https://www.scirp.org/(S(351jmbntvnsjt1aadkposzje))/reference/ReferencesPapers.aspx?ReferenceID=534264

Cihak, M., Mare, D., \& Melecky, M. (2016). The nexus of financial inclusion and financial stability: a study of trade-offs and synergies. Policy Research Working Paper 7722, World Bank Group. Retrieved from http://documents.worldbank.org/curated/en/138991467994676130/pdf/WPS7722.pdf

Fornell, C., \& Larcker, D. (1981). Evaluating structural equation models with unobservable variables and measurement error. Journal of Marketing Research, 18, 39-50. https://doi.org/10.2307/3151312

Hair, J., Black, W., Babin, B., Anderson, R., \& Tatham, R. (2006). Multivariate Data Analysis. Pearson Education, New Jersey.

Hair, J., Sarstedt, M., Hopkins, L., \& Kuppelwieser, V. (2014). Partial least squares structural equation modelling: an emerging tool in business research. European Business Review, 26(2), 106-121. https://doi.org/10.1108/EBR-10-2013-0128

Henseler, J., Ringle, C., \& Sarstedt, M. (2015). A new criterion for assessing discriminant validity in variance-based structural equation modelling. Journal of the Academy of Marketing Science, 43(1), 115-135. 
https://doi.org/10.1007/s11747-014-0403-8

Kim, J. (2016). A study on the effect of financial inclusion on the relationship between income inequality and economic growth. Emerging Markets Finance and Trade, 52, 498-512. https://doi.org/10.1080/1540496X.2016.1110467

Kline, R. (1998). Principles and practice of structural equation modelling. Guilford Press, NY.

Kodan, A., \& Chhikara, K. (2013). A theoretical and quantitative analysis of financial inclusion and economic growth. Management and Labour Studies, 38(1-2). https://doi.org/10.1177/0258042X13498009

Limayem, M., Hirt, S., \& Cheung, C. (2007). How habit limits the predictive power of intention: the case of information systems continuance. MIS Quarterly, 31(4), 705-737. https://doi.org/10.2307/25148817

Mahapatra, M., Raveendran, J., \& De, A. (2019). Building a model on influence of behavioural and cognitive factors on personal financial planning: a study among Indian households. Global Business Review, 1-14. Retrieved from https://econpapers.repec.org/article/saeglobus/v_3a20_3ay_3a2019_3ai_3a4_3ap_3a996-1009.htm

Mani, M. (2016). Financial inclusion in South Asia - relative standing, challenges and initiatives. South Asian Survey, 23(2), 158-179. https://doi.org/10.1177/0971523118783353

Marsh, H., \& Hau, K. (1996). Assessing goodness of fit: is parsimony always desirable?. Journal of Experimental Education, 64, 364-390. https://doi.org/10.1080/00220973.1996.10806604

Miotto, A., \& Parente, J. (2015). Antecedents and consequences of household financial management in Brazilian lower middle class. Sao Paulo, 55(1), 50-64. https://doi.org/10.1590/S0034-759020150106

Mukhopadhyay, J. (2016). Financial inclusion in India: a demand-side approach. Economic and Political Weekly, 51(46). Retrieved from https://www.epw.in/journal/2016/49/special-articles/financial-inclusion-india.html

Nandru, P., Byram, A., \& Rentala, S. (2016). Determinants of financial inclusion: evidence from account ownership and use of banking services. International Journal of Entrepreneurship and Development Studies, 4(2), 141-155. Retrieved

from https://www.researchgate.net/publication/301731430_Determinants_of_financial_inclusion_Evidence_from_ac ount_ownership_and_use_of_banking_services

Panda, D. (2019). Misaligned expectations and non-cooperative behaviour in Indian microfinance: evidence from a survey. Journal of Economic Issues, 53(1), 211-233. https://doi.org/10.1080/00213624.2019.1573087

Rangarajan, C. (2008). Report of the Committee on Financial Inclusion. Government of India, New Delhi.

Ranjani, K., \& Bapat, V. (2015). Deepening financial inclusion beyond account opening: road ahead for banks. Business Perspectives and Research, 3(1), 52-65. https://doi.org/10.1177/2278533714551864

Riitsalu, L. (2018). Goals, commitment and peer effects as tools for improving the behavioural outcomes of financial education. Citizenship, Social and Economics Education, 1-22. https://doi.org/10.1177/2047173418812045

Ringle, C., Wende, S., \& Becker, J. (2015). SmartPLS 3. Bonningstedt: SmartPLS.

Sinha, D., \& Azad, R. (2018). Dhan Yojana achieve financial inclusion?. Economic and Political Weekly, 53(13). Retrieved from https://www.epw.in/journal/2018/13/money-banking-and-finance/can-jan-dhan-yojana-achieve-financial-inclusi on.html

Tulasi, G., Golait, R., Sethi, M., \& Goel, S. (2017). Involuntary exclusion and the formal financial sector. Economic and Political Weekly, 52(36), 67-72. Retrieved from https://www.epw.in/journal/2017/36/notes/involuntary-exclusion- and-formal-financial-sector.html

Zinser, B. (2019). Retail Islamic banking and financial services determinants of use by Muslims in the USA. Journal of Islamic Marketing, 10(1), 168-190.

\section{Copyrights}

Copyright for this article is retained by the author(s), with first publication rights granted to the journal.

This is an open-access article distributed under the terms and conditions of the Creative Commons Attribution license (http://creativecommons.org/licenses/by/4.0/). 